\title{
Comparative study of DNA extraction methods for identification of medicinal mushrooms
}

\author{
Petya Stefanova ${ }^{1, *}$, Mariya Brazkova ${ }^{1}$, and Galena Angelova ${ }^{1}$ \\ Department of Biotechnology, University of Food Technologies, Plovdiv, Bulgaria
}

\begin{abstract}
The isolation of high quantity and intact DNA is of a great significance for molecular identification of higher fungi. The aim of this study was to compare two DNA extraction methods for isolation of DNA from medicinal mushrooms of Agaricomycetes class. A modified CTAB method and a modified SDS method were compared by the yield and purity of the extracted DNA, its fragmentation state and suitability for amplification. The results demonstrated high efficiency of both methods in regard to DNA yield (14.18 - 144.28 ng DNA/mg biomass with CTAB method and 15.03 - $108.34 \mathrm{ng}$ DNA/mg biomass with SDS method). The CTAB method provided DNA extracts with higher purity (A260/A280 ranged from 1.83 to 1.99$)$ in comparison with the SDS method (A260/A280 = $1.53-1.86)$. The modified CTAB method produced amplifiable DNA from all mushroom isolates, while the SDS method demonstrated suitability for amplification only in $50 \%$ of the samples. Therefore, the modified CTAB method could be the method of choice for DNA extraction from medicinal mushrooms. The analyzed isolates were subjected to molecular identification by ITS1-5.8S-ITS2 rRNA gene sequence analysis and were identified as Ganoderma resinaceum, Trametes versicolor, Fomitopsis pinicola and Inonotus hispidus.
\end{abstract}

\section{Introduction}

Since ancient time, mushrooms are of interest as a source of nutrients and medicines [1]. Medicinal mushrooms most of which belong to the higher basidiomycetes are an exceptionally diverse group part of the fungal kingdom. The secondary metabolites of the basidiomycetes from genera Agaricus, Auricularia, Phellinus, Ganoderma, Pleurotus, Trametes and Lentinus and their biological activities have seen a marked main reason for the increased scientific interest regarding their application [2].

Because of their high sensitivity and specificity, the PCR based molecular techniques has become a preferable method for identification and characterization of medical mushrooms [3]. One of the most widely used barcoding regions of fungi is the internal transcribed spacer (ITS) region and up to date, a large number of fungal ITS region sequences have been deposited in public databases [4]. ITS combines the highest resolution for discriminating closely related species with a high PCR and sequencing success rate across a vast range of fungi [5]. ITS regions may be amplified by PCR and sequenced afterwards for molecular phylogenetic analysis in various fungal species [6]. The research of population genetics and biodiversity of mushroom species rely on DNA sequences obtained by PCR [7].

The major challenge for a successful amplification is the efficiency of the DNA extraction step [8]. The ultimate sensitivity of any PCR assay for fungal detection relies on effective lysis of fungal cells and DNA purification from PCR inhibitors [9]. Most extraction methods include mechanical or physical-mechanical techniques for the disruption of the cell wall, such as grinding in liquid nitrogen, alternating freezing and thawing, disruption with glass beads and microwave radiation [10]. CTAB and SDS extraction buffers are also usually used for extraction of genomic DNA, followed by purification through extraction with phenol/chloroform and precipitation with isopropyl or ethyl alcohol [3]. In addition, most methods use enzymes for digesting the cell wall [11]. Cellulases, chitinases or lysozyme could be used in that matter depending on the characteristics of the cell wall [10]. Proteinase K and RNase A are often used for removing proteins and RNA, respectively [9].

Numerous DNA extraction protocols are available to date, but most of these protocols and techniques distinguished in quality and quantity of DNA when are applied on different fungi. Therefore, the aim of the present study was to compare two DNA extraction methods for isolation of DNA from medicinal mushrooms of Agaricomycetes class.

\section{Materials and methods}

\subsection{Analysed samples}

Four newly isolated mushrooms of Agaricomycetes class were analyzed in this study. The fungal basidiocarps were 
collected from different trees and regions in Bulgaria and were obtained as pure mycelium cultures which were maintained on Mushroom Complete medium (MCM), with the following composition $(\mathrm{g} / \mathrm{L})$ : glucose 20.0, $\mathrm{KH}_{2} \mathrm{PO}_{4} 0.5, \mathrm{~K}_{2} \mathrm{HPO}_{4} 1.0, \mathrm{MgSO}_{4} 0.5$, peptone 2.0, yeast extract 2.0, agar 2.0, pH $4.8-5.2$ at $4^{\circ} \mathrm{C}$ and renewed every 30 days. Trametes versicolor ATCC 200801 was used as a positive control for ITS1-5.8S-ITS2 rRNA gene sequence analysis. Isolates $1.1,2.1,3.1$ and 4.1 were cultivated on agar plates for obtaining of aerial mycelium. Isolates $1.2,2.2,3.2$ and 4.2 were cultivated in liquid broth for pellets production.

\subsection{DNA extraction}

Prior to DNA extraction, the studied mushrooms were grown on $\mathrm{MCM}$ agar plates at $25^{\circ} \mathrm{C}$ in dark until agar surface was fully covered with aerial mycelium. Liquid mycelia culture (pellets) was obtained in MCM broth by shaking at $220 \mathrm{rpm}$ for 7 to 9 days. The aerial mycelium was scraped out and the pellets were washed aseptically, and then transferred into a $2 \mathrm{ml}$ microtube. The extraction of DNA was performed according to the modified CTAB method [12] and SDS method [3] with some modifications.

\subsection{DNA concentration, purity and fragmentation state}

The concentration and purity of the DNA extracts were assessed spectrophotometrically by measuring the absorbance at $260 \mathrm{~nm}$ and determining the ratio of the absorbance at $260 \mathrm{~nm}$ and $280 \mathrm{~nm}$, respectively (Shimadzu UV-VIS, Shimadzu Corporation, Japan). The fragmentation state of the extracted DNA was evaluated by electrophoresis in $1 \%$ agarose with $0.5 \mathrm{x}$ TBE buffer, stained with Safe View Nucleic Acid Stain (NBS Biologicals, Huntingdon, England) for $60 \mathrm{~min}$. at $100 \mathrm{~V}$. The visualization of the agarose gel was performed under UV light, with MiniBIS Pro Gel documentation system (DNR Bio-Imaging Systems, Jerusalem, Israel).

\subsection{Molecular identification of newly isolated medicinal mushrooms by ITS1-5.8S-ITS2 region sequence analysis}

The amplification of ITS-5.8S-ITS2 region was done by primers ITS 4 (5'-TCCTCCGCTTATTGATATGC-3') and ITS 5 (5'-GGAAGTAAAAGTGCTAACAAGG-3') [4], obtained from Metabion (Martinsried, Germany). The PCR reaction was performed in a final volume of $20 \mu \mathrm{l}$, containing $1 \mu \mathrm{l}$ of DNA (50 ng), $0.5 \mu \mathrm{M}$ of each primer and $8 \mu \mathrm{l}$ of Red-Taq DNA Polymerase Master Mix (Canvax Biotech, S.L., Spain). The parameters of amplification were initial denaturation at $95^{\circ} \mathrm{C}$ for $10 \mathrm{~min}$, followed by 35 cycles of denaturation at $95^{\circ} \mathrm{C}$ for $1 \mathrm{~min}$, annealing at $52^{\circ} \mathrm{C}$ for $1 \mathrm{~min}$, extension at $72^{\circ} \mathrm{C}$ for $1 \mathrm{~min}$, and final extension at $72^{\circ} \mathrm{C}$ for $7 \mathrm{~min}$. The amplification was carried out in a PCR 2720 Thermal Cycler (Applied Biosystems, USA). The separation of PCR products was conducted in 1\% agarose gel stained with SafeView (NBS
Biologicals, Huntingdon, England) at $100 \mathrm{~V}$ for $50 \mathrm{~min}$ using VWR Mini Electrophoresis System (VWR, Germany) and MiniBis Pro (DNR Bio-Imaging Systems, Israel) for gel visualization.

The PCR products were purified with Clean-Easy ${ }^{\mathrm{TM}}$ Agarose Purification Kit (Canvax Biotech, S.L., Spain) according to the manufacturer's instructions. Sequencing of the PCR products was performed by Microsynth Seqlab (Göttingen, Germany). The resulting sequences were analyzed using BLAST algorithm [13] and compared with the nucleotide sequences in the GenBank database (www.ncbi.nlm.nih.gov).

\subsection{Statistical analysis}

One-way ANOVA was performed to assess the differences between DNA yields obtained with each extraction method. The $p$-value determined the significant differences.

\subsection{Molecular identification of newly isolated medicinal mushrooms by ITS1-5.8S-ITS2 region sequence analysis}

The amplification of ITS-5.8S-ITS2 region was done by primers ITS 4 (5'-TCCTCCGCTTATTGATATGC-3') and ITS 5 (5'-GGAAGTAAAAGTGCTAACAAGG-3') [4], obtained from Metabion (Martinsried, Germany). The PCR reaction was performed in a final volume of $20 \mu \mathrm{l}$, containing $1 \mu \mathrm{l}$ of DNA (50 ng), $0.5 \mu \mathrm{M}$ of each primer and $8 \mu \mathrm{l}$ of Red-Taq DNA Polymerase Master Mix (Canvax Biotech, S.L., Spain). The parameters of amplification were initial denaturation at $95^{\circ} \mathrm{C}$ for $\quad 10$ min, followed by 35 cycles of denaturation at $95^{\circ} \mathrm{C}$ for 1 min, annealing at $52^{\circ} \mathrm{C}$ for $1 \mathrm{~min}$, extension at $72^{\circ} \mathrm{C}$ for 1 min, and final extension at $72^{\circ} \mathrm{C}$ for $7 \mathrm{~min}$. The amplification was carried out in a PCR 2720 Thermal Cycler (Applied Biosystems, USA). The separation of PCR products was conducted in $1 \%$ agarose gel stained with SafeView (NBS Biologicals, Huntingdon, England) at $100 \mathrm{~V}$ for $50 \mathrm{~min}$ using VWR Mini Electrophoresis System (VWR, Germany) and MiniBis Pro (DNR BioImaging Systems, Israel) for gel visualization.

The PCR products were purified with Clean-Easy ${ }^{\mathrm{TM}}$ Agarose Purification Kit (Canvax Biotech, S.L., Spain) according to the manufacturer's instructions. Sequencing of the PCR products was performed by Microsynth Seqlab (Göttingen, Germany). The resulting sequences were analyzed using BLAST algorithm [13] and compared with the nucleotide sequences in the GenBank database (www.ncbi.nlm.nih.gov)

\section{Results and Discussion}

\subsection{DNA concentration, purity and yield}

The isolation of high quantity and intact DNA is of a great significance for molecular identification of higher fungi. A modified CTAB method and a modified SDS method 
Table 1. Concentration and purity of DNA extracts from newly isolated medicinal mushrooms, obtained with CTAB method and SDS method.

\begin{tabular}{|c|c|c|c|c|}
\hline № & Fungal isolate & Extraction method & $\mathrm{C}_{\text {DNA }}, \mathrm{ng} / \boldsymbol{\mu l} \pm \mathrm{SD}$ & $\mathbf{A}_{260 / 280} \mathrm{~nm} \pm \mathrm{SD}$ \\
\hline \multirow{2}{*}{1} & \multirow{2}{*}{ Isolate 1.1} & CTAB & $288.56 \pm 8.94$ & $1.90 \pm 0.05$ \\
\hline & & SDS & $63.03 \pm 5.1$ & $1.54 \pm 0.04$ \\
\hline \multirow{2}{*}{2} & \multirow{2}{*}{ Isolate 1.2} & CTAB & $78.99 \pm 5.18$ & $1.99 \pm 0.01$ \\
\hline & & SDS & $30.06 \pm 2.83$ & $1.83 \pm 0.03$ \\
\hline \multirow{2}{*}{3} & \multirow{2}{*}{ Isolate 2.1} & CTAB & $83.1 \pm 3.6$ & $1.99 \pm 0.01$ \\
\hline & & SDS & $119.21 \pm 7.91$ & $1.76 \pm 0.08$ \\
\hline \multirow{2}{*}{4} & \multirow{2}{*}{ Isolate 2.2} & CTAB & $38.81 \pm 1.15$ & $1.91 \pm 0.08$ \\
\hline & & SDS & $54.23 \pm 6.05$ & $1.58 \pm 0.01$ \\
\hline \multirow{2}{*}{5} & \multirow{2}{*}{ Isolate 3.1} & CTAB & $55.2 \pm 3.8$ & $1.83 \pm 0.05$ \\
\hline & & SDS & $38.35 \pm 2.14$ & $1.53 \pm 0.05$ \\
\hline \multirow{2}{*}{6} & \multirow{2}{*}{ Isolate 3.2} & CTAB & $28.36 \pm 2.86$ & $1.99 \pm 0.01$ \\
\hline & & SDS & $37.63 \pm 2.25$ & $1.71 \pm 0.03$ \\
\hline \multirow{2}{*}{7} & \multirow{2}{*}{ Isolate 4.1} & CTAB & $192.71 \pm 4.28$ & $1.97 \pm 0.03$ \\
\hline & & SDS & $216.67 \pm 9.12$ & $1.84 \pm 0.01$ \\
\hline \multirow{2}{*}{8} & \multirow{2}{*}{ Isolate 4.2} & CTAB & $176.47 \pm 4.77$ & $1.96 \pm 0.01$ \\
\hline & & SDS & $153.83 \pm 7.94$ & $1.86 \pm 0.05$ \\
\hline
\end{tabular}

were compared by the yield and purity of the extracted DNA. The data from the spectrophotometric measurement of DNA concentration and purity are summarized in Table 1 . The results showed that both extraction methods produced DNA extracts with high quantity. Concentrations varied between 28.36 - 288.56 ng DNA/ $\mu$ l DNA with CTAB method and between 30.06 - 216.67 ng DNA/ $\mu$ I DNA with SDS method. The presented data were in agreement with other authors as Nagappan et al. [14], Bencina et al. [15] and Vlasenko et al. [16].

The CTAB method provided DNA extracts with higher purity $\left(\mathrm{A}_{260} / \mathrm{A}_{280}\right.$ ranged from 1.83 to 1.99$)$ in comparison with the SDS method $\left(\mathrm{A}_{260} / \mathrm{A}_{280}=1.53-\right.$ 1.86), which corresponded to the results obtained by Mot'ková et al. [10] and Rodrigues et al. [17]. The purity of the DNA extracts obtained with CTAB method in the present work was higher than the data presented by Zhou et al. [18].

According to Rodrigues et al., the purity of the extracts obtained by the SDS method was inappropriate as the ratio $\mathrm{A}_{260} / \mathrm{A}_{280}$ was less than 1.6 [17]. The results from the spectrophotometric analysis clearly showed the higher efficiency of the CTAB method in comparison with SDS method.

The total amounts of DNA obtained from newly isolated medicinal mushrooms with CTAB method and SDS method are presented in Figure 1. The results demonstrated high efficiency of both methods in regard to DNA yield (14.18 - $144.28 \mathrm{ng}$ DNA/mg biomass with CTAB method and 15.03 - 108.34 ng DNA/mg biomass with SDS method). The average amounts of DNA obtained per mg biomass were verified with other studies with higher fungi [14, 15, 17].

One-way ANOVA was performed to assess the differences between DNA yields obtained with each extraction method. The results demonstrated significant differences between the extraction methods for isolates
$1.1,1.2,2.1,2.2,3.1,3.2$ and 4.2 , as the $p$-value was less than 0.05 . On the other hand, no significant differences were observed for isolate $4.1(p=0.0939)$.

\subsection{DNA fragmentation state}

The isolation of intact DNA is of a great significance for further PCR amplification of fungal DNA. The fragmentation state of the fungal extracts was evaluated based on the fragment size of the obtained DNA. Figure 2 shows an agarose gel electrophoresis of DNA extracts from newly isolated medicinal mushrooms, obtained with CTAB and SDS method.

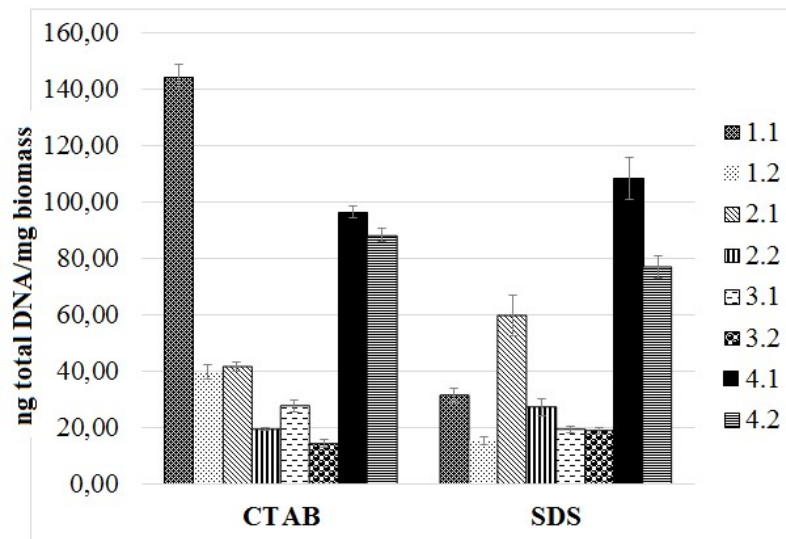

Fig. 1. Total amounts of DNA obtained from newly isolated medicinal mushrooms with $\mathrm{CTAB}$ method and SDS method.

High molecular weight DNA fragments with size over 10000 bp were observed in isolates $1.1,1.2,2.1,2.2,3.1$ and 3.2 in the case of DNA extracts obtained with CTAB method ( $75 \%$ of the analyzed samples). The lack of intact DNA in isolates 4.1 and 4.2 demonstrated a higher degree of DNA fragmentation (Fig. 2A). Similar results were obtained with SDS extraction method, which produced high molecular weight DNA in $75 \%$ of the DNA extracts. 
However, a significantly lower intensity of the obtained fragments was observed, which corresponded to the lower DNA concentrations obtained from the spectrophotometric analysis. The presence of DNA with preserved integrity was not found in isolates 3.1 and 4.2 obtained by SDS method.
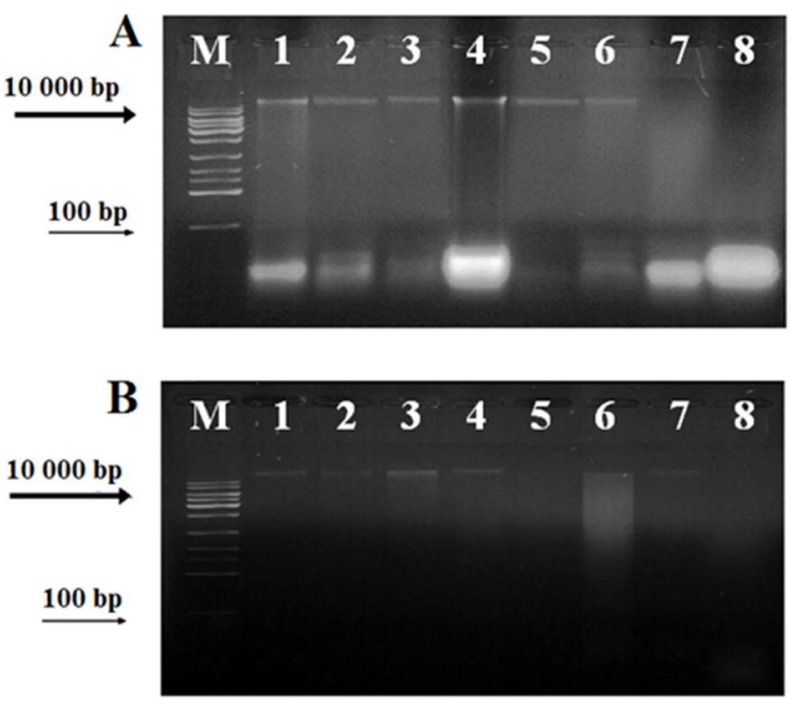

Fig. 2. Agarose gel electrophoresis of DNA extracts from newly isolated medicinal mushrooms, obtained with $\mathrm{CTAB}$ method (A) and SDS method (B). M: DNA ladder; 1: isolate 1.1; 2: isolate $1.2 ; 3$ : isolate $2.1 ; 4$ : isolate $2.2 ; 5$ : isolate $3.1 ; 6$ : isolate $3.2 ; 7$ : isolate $4.1 ; 8$ : isolate 4.2 .

The received data were in agreement with other reports. According to Abu Almakarem et al., the degree of DNA fragmentation state largely depends on the age of the culture subjected to extraction [19]. In addition, the purification of the DNA extracts from the lysing chemicals used in the initial stages of extraction and the storage conditions of the obtained DNA extracts were very important [20].

\subsection{PCR amplification}

The DNA extracts from all fungal isolates were further subjected to PCR analysis in order to confirm their suitability for amplification. Figure 3 represents the agarose gel electrophoresis of PCR products of DNA extracts from newly isolated medicinal mushrooms obtained with both extraction methods. All DNA extracts obtained with the CTAB method were successfully amplified and produced PCR products with approximate size of about $700 \mathrm{bp}$ (isolates 1.1, 1.2, 2.1, 2.2, 4.1 and 4.2) and about $900 \mathrm{bp}$ (isolates 3.1 and 3.2).

In contrast to the CTAB method, the DNA extracts obtained with SDS method provided positive amplification only in the case of pellets with vegetative mycelium (Fig. 2B, lanes 2, 4, 6 and 8). The absence of amplified PCR fragments in the DNA extracts of aerial mycelium from all fungal isolates clearly demonstrated that they were not suitable for PCR amplification (Fig. 2B, lanes 1, 3, 5 and 7).

The obtained results were in agreement with other authors [3, 20, 21]. During the isolation and identification of white rot fungi the mentioned authors amplified PCR products with approximate size of about $700 \mathrm{bp}$ in DNA extracts from Trametes versicolor, Inonotus pachyphloeus, Pleurotus erynji and Pleurotus sajor-caju, respectively. The reported extraction methods ranged from various commercial kits to different modifications of the CTAB and SDS methods.
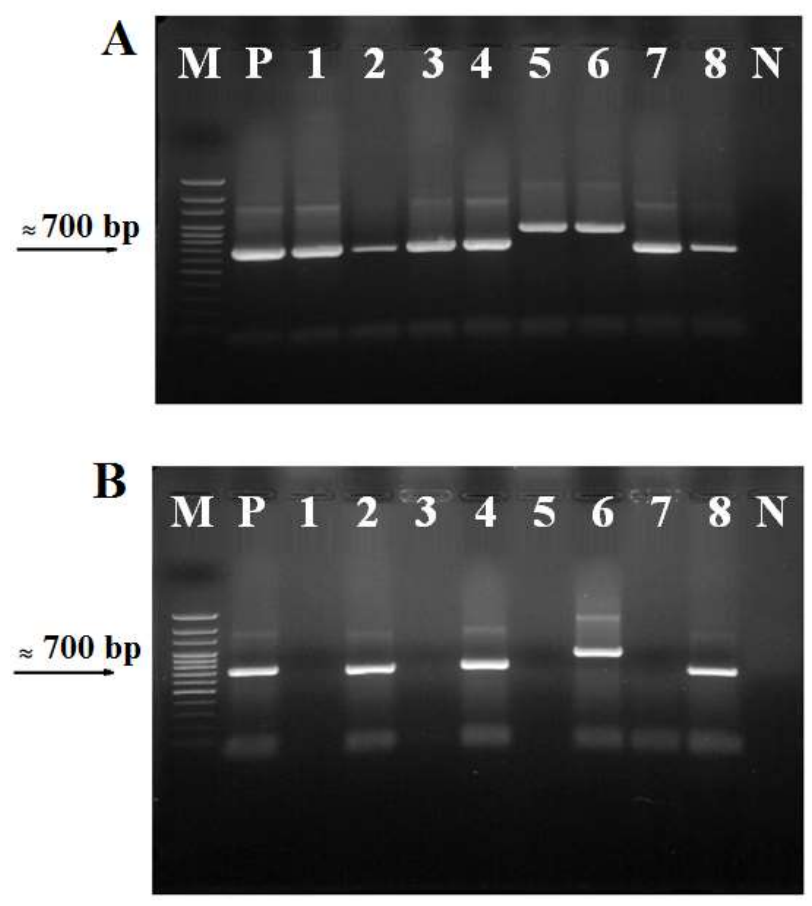

Fig. 3. Agarose gel electrophoresis of PCR products of DNA extracts from newly isolated medicinal mushrooms obtained with CTAB method (A) and SDS method (B). M: DNA ladder; $\mathrm{P}$ : positive control; 1 : isolate $1.1 ; 2$ : isolate $1.2 ; 3$ : isolate $2.1 ; 4$ : isolate $2.2 ; 5$ : isolate $3.1 ; 6$ : isolate $3.2 ; 7$ : isolate $4.1 ; 8$ : isolate $4.2 ; \mathrm{N}$ : negative PCR control.

PCR fragments were not detected in the negative controls, which indicated the absence of nonspecific amplification and confirmed the specificity of the method.

In summary, the comparative study of both DNA extraction methods (CTAB method and SDS method) in terms of concentration, purity, yield, fragmentation state and suitability for amplification clearly demonstrated the advantages of the CTAB method for DNA extraction from medicinal mushrooms.

\subsection{Molecular identification of newly isolated medicinal mushrooms by ITS1-5.8S-ITS2 region sequence analysis}

Molecular identification of newly isolated medicinal mushrooms was performed by amplification of ITS15.8S-ITS2 region. Further, the obtained PCR products were subjected to sequence analysis and the sequences were analyzed using BLAST algorithm and compared with the nucleotide sequences in the GenBank database (www.ncbi.nlm.nih.gov). The results from molecular identification are presented in Table 2. The fungal strains were identified with high percent of confidence $(99.12$ $99.66 \%)$ as Ganoderma resinaceum, Fomitopsis 
pinicola, Inonotus hispidus and Trametes versicolor. The ITS1-5.8S-ITS2 rRNA gene sequences of the analyzed medical mushrooms were deposited in the GenBank under their respective accession numbers (Table 2).

Molecular identification of newly isolated medicinal mushrooms demonstrated that the analyzed fungal strains referred to the genera Ganoderma, Fomitopsis, Inonotus and Trametes, which belonged to the group of basidiomycete fungi with significant medicinal application.

Table 2. Molecular identification of newly isolated medical mushrooms by ITS1-5.8S-ITS2 rRNA gene sequence analysis.

\begin{tabular}{|c|c|c|c|}
\hline № & $\begin{array}{c}\text { Fungal } \\
\text { isolate }\end{array}$ & $\begin{array}{c}\text { Closest relative } \\
\text { (identity, \%) }\end{array}$ & $\begin{array}{c}\text { GenBank } \\
\text { accession no. }\end{array}$ \\
\hline 1 & Isolate 1 & $\begin{array}{c}\text { Ganoderma } \\
\text { resinaceum (99.66) }\end{array}$ & MW996757 \\
\hline 2 & Isolate 2 & $\begin{array}{c}\text { Fomitopsis pinicola } \\
(99.52)\end{array}$ & MW996756 \\
\hline 3 & Isolate 3 & $\begin{array}{c}\text { Inonotus hispidus } \\
(99.12)\end{array}$ & MW996758 \\
\hline 4 & Isolate 4 & $\begin{array}{c}\text { Trametes versicolor } \\
(99.35)\end{array}$ & MZ853847 \\
\hline
\end{tabular}

\section{Conclusions}

The present work demonstrated that the modified CTAB method could be the method of choice for DNA extraction from medicinal mushrooms. This scientific work is of general public interest as it revealed the diversity of medicinal mushrooms in different areas of Bulgaria. Molecular genetic identification of the newly isolated fungal strains allowed a more extensive analysis of the growing conditions in order to obtain various valuable and healthy metabolites and nutraceuticals.

Acknowledgements: The study was funded by The Bulgarian National Science Fund under contract No КП-06H37/4 and by Bulgarian Ministry of Education and Science under the National Research Programme "Healthy Foods for a Strong Bio-Economy and Quality of Life" approved by DCM \# 577/17.08.2018".

\section{References}

1. R. Varghese, Y.B. Dalvi, P.Y. Lamrood, B.P. Shinde, C.K.K. Nair, 3 Biotech. 9, 362 (2019)

2. M.D. Asatiani, V. Elisashvili, G. Songulashvili, A.Z. Reznick, S.P. Wasser, Progress in Mycology (Springer, Dordrecht, 2010)

3. S. Aamir, Plant Pathol. Quar. J. Fungal. Biolog. 5, 7481 (2015).

4. H. Toju, A.S. Tanabe, S. Yamamoto, H. Sato, PLoS One. 7, 0040863 (2012)

5. C.L. Schoch, K.A. Seifert, S. Huhndorf, V. Robert, J. L. Spouge, C.A. Levesque, W. Chen, E. Bolchacova, K. Voigt, P.W. Crous, A.N. Miller, M.J. Wingfield,
M.C. Aime, K.D An, F.Y. Bai, R.W. Barreto, D. Begerow, M. J. Bergeron, M. Blackwell, D. Schindel, PNAS. 109, 6241-6246 (2012)

6. Q.X. Wu, G.M. Mueller, F.M. Lutzoni, Y.Q. Huang, S.Y. Guo, Mol. Phylogenet. Evol. 17, 37-47 (2000)

7. K. Izumitsu, , K. Hatoh, , T. Sumita, Y. Kitade, A. Morita, C. Tanaka, A. Gafur, A. Ohta, M. Kawai, T. Yamanaka, H. Neda, Y. Ota, Mycosci. 53, 396-401 (2012)

8. E. Anklam, F. Gadani, P. Heinze, H. Pijnenburg, G. Van Den Eede, Eur. Food Res. Technol. 214, 3-26 (2002)

9. D.N. Fredricks, C. Smith, A. Meier, J. Clin. Microbiol. 43, 5122-5128 (2005)

10. P. Mot'ková, J. Vytřasová, J. Food Sci. 29, 76-85 (2011)

11. J. Jin, Y. Lee, B.L. Wickes, J. Clin. Microbiol. 42, 4293-4296 (2004)

12. P. Stefanova, M. Taseva, T. Georgieva, V. Gotcheva, A. Angelov, Biotechnol. Biotechnol. Equip. 27, 3803-3810 (2013)

13. S.F. Altschul, W. Gish, W. Miller, E.W. Myers, D.J. Lipman, J. Mol. Biol. 215, 403-410 (1990)

14. J. Nagappan, C.F. Chin, L.P.L. Angel, R.M. Cooper, S.T. May, E.T.L Low, Biotechnol. Lett. 40, 15411550 (2018)

15. M. Benčina, M. Jakopič, J. Friedrich, Acta Chim. Slov. 54, 893-899 (2007)

16. V. Vlasenko, S. Asbaganov, A. Vlasenko, BIO Web Conf. 16, 38 (2019)

17. P. Rodrigues, A. Venâncio, N. Lima, Lett. Appl. Microbiol. 66, 32-37 (2018)

18. X. Zhou, Q. Li, J. Zhao, K. Tang, J. Lin, Y. Yin, Prep. Biochem. Biotechnol. 37, 369-380 (2007)

19. A.S. Abu Almakarem, K.L. Heilman, H.L. Conger, Y.M. Shtarkman, S.O. Rogers, BMC Res. Notes. 5, $266(2012)$

20. F.A. Avin, S. Bhassu, V. Sabaratnam, Res. Crop. 14, 897-901 (2013)

21. C.A. Jasalavich, A. Ostrofsky, J. Jellison, Appl. Environ. Microbiol. 66, 4725-4734 (2000) 